\title{
Transforaminal endoscopic surgery for symptomatic lumbar disc herniations: a systematic review of the literature
}

\author{
Jorm Nellensteijn $\cdot$ Raymond Ostelo $\cdot$ Ronald Bartels • \\ Wilco Peul · Barend van Royen · Maurits van Tulder
}

Received: 11 March 2009/Revised: 29 June 2009/Accepted: 19 August 2009/Published online: 15 September 2009

(C) The Author(s) 2009. This article is published with open access at Springerlink.com

\begin{abstract}
The study design includes a systematic literature review. The objective of the study was to evaluate the effectiveness of transforaminal endoscopic surgery and to compare this with open microdiscectomy in patients with symptomatic lumbar disc herniations. Transforaminal endoscopic techniques for patients with symptomatic lumbar disc herniations have become increasingly popular. The literature has not yet been systematically reviewed. A comprehensive systematic literature search of the MEDLINE and EMBASE databases was performed up to May 2008. Two reviewers independently checked all retrieved titles and abstracts and relevant full text articles for inclusion criteria. Included articles were assessed for quality and outcomes were extracted by the two reviewers independently. One randomized controlled trial, 7 non-randomized controlled trials and 31 observational studies were identified. Studies were heterogeneous regarding patient selection, indications, operation techniques, follow-up period
\end{abstract}

J. Nellensteijn

Department of Orthopaedics, EMGO Institute, VU University

Medical Center, Amsterdam, The Netherlands

R. Ostelo $(\square) \cdot$ M. van Tulder

Department of Health Sciences, EMGO Institute, VU University

Medical Center, VU University, De Boelelaan 1085, room U-430, 1081 HV Amsterdam, The Netherlands

e-mail: r.ostelo@vumc.nl

W. Peul

Leiden University Medical Center, Leiden, The Netherlands

R. Bartels

Department of Neurosurgery, Radboud University Nijmegen

Medical Centre, Nijmegen, The Netherlands

B. van Royen

VU University Medical Center, Amsterdam, The Netherlands and outcome measures and the methodological quality of these studies was poor. The eight trials did not find any statistically significant differences in leg pain reduction between the transforaminal endoscopic surgery group (89\%) and the open microdiscectomy group (87\%); overall improvement ( 84 vs. $78 \%$ ), re-operation rate (6.8 vs. $4.7 \%$ ) and complication rate (1.5 vs. $1 \%)$, respectively. In conclusion, current evidence on the effectiveness of transforaminal endoscopic surgery is poor and does not provide valid information to either support or refute using this type of surgery in patients with symptomatic lumbar disc herniations. High-quality randomized controlled trials with sufficiently large sample sizes are direly needed to evaluate if transforaminal endoscopic surgery is more effective than open microdiscectomy.

Keywords Lumbar disc herniation - Transforaminal . Endoscopic surgery · Minimally invasive surgery · Systematic review

\section{Introduction}

Surgery for lumbar disc herniation can be classified into two broad categories: open versus minimally invasive surgery and posterior versus posterolateral approaches. Mixter and Barr in 1934 were the first authors to treat lumbar disc herniation surgically by performing an open laminectomy and discectomy [41]. With the introduction of the microscope, Caspar and Yasargil refined the original laminectomy into open microdiscectomy [4, 63]. Laminectomy and microdiscectomy are open procedures using a posterior approach. Currently, open microdiscectomy is the most widespread procedure for surgical decompression of radiculopathy caused by lumbar disc herniation, but 
minimally invasive surgery has gained a growing interest. The concept of minimally invasive surgery for lumbar disc herniations is to provide surgical options that optimally address the disc pathology without producing the iatrogenic morbidity associated with the open surgical procedures. In the last decades, endoscopic techniques have been developed to perform discectomy under direct view and local anaesthesia.

Kambin and Gellmann in 1973 [22] in the United States and Hijikata in Japan in 1975 [12], independently performed a non-visualised, percutaneous central nucleotomy for the resection and evacuation of nuclear tissue via a posterolateral approach. In 1983, Forst and Housman reported the direct visualization of the intervertebral disc space with a modified arthroscope [9]. Kambin published the first intraoperative discoscopic view of a herniated nucleus pulposus in 1988 [21]. In 1989 and 1991 Schreiber et al. described 'percutaneous discoscopy', a biportal endoscopic posterolateral technique with modified instruments for direct view [52, 55]. In 1992, Mayer introduced percutaneous endoscopic laser discectomy combining forceps and laser [40]. With the further improvement of scopes (e.g. variable angled lenses and working channel for different instruments), the procedure became more refined. The removal of sequestered non-migrated fragments became possible using a biportal approach [25]. The concept of posterolateral endoscopic lumbar nerve decompression changed from indirect central nucleotomy (inside out, in which fragments are extracted through an annular fenestration outside the spinal canal) to transforaminal direct extraction of the non-contained and sequestered disc fragments from inside the spinal canal. In this article, the technique of direct nucleotomy is described as intradiscal and the technique directly in the spinal canal is described as intracanal technique; both are transforaminal approaches (Fig. 1).

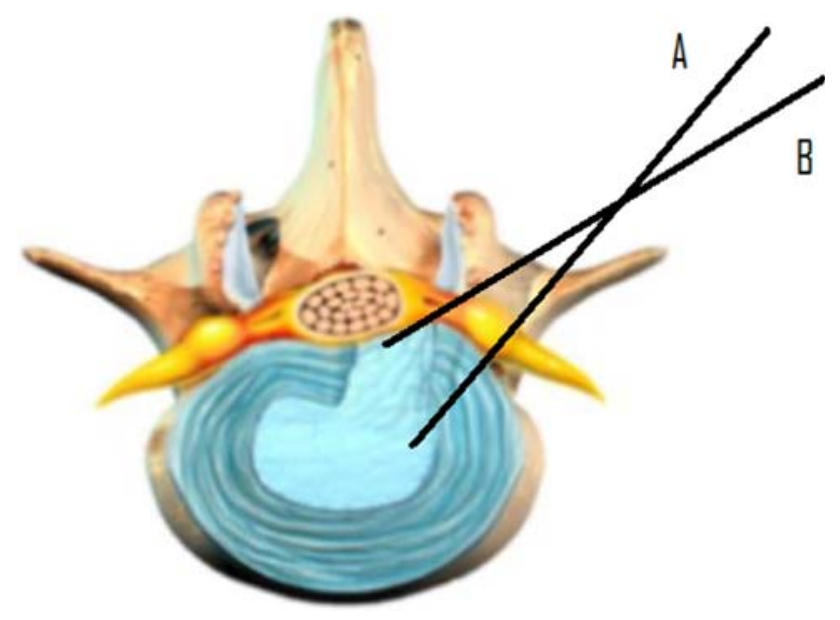

Fig. 1 Different posterolateral approaches to the lumbar disc. a The intradiscal technique, $\mathbf{b}$ the intracanal technique
The indications for transforaminal endoscopic treatment are the same as classical discectomy procedures $[6,24,38]$. To reach the posterior part of the epidural space, the superior articular process of the facet joint is usually the obstacle. Yeung and Knight used a holmium-YAG (yttrium-aluminium-garnet)-laser for ablation of bony and soft tissue for decompression, enhanced access and to improve intracanal visualisation [30,64]. Yeung developed the commercially available Yeung Endoscopic Spine System (YESS) in 1997 [65] and Hoogland in 1994 developed the Thomas Hoogland Endoscopic Spine System (THESSYS). With this latter system, it is possible to enlarge the intervertebral foramen near the facet joint with special reamers to reach intracanal extruded and sequestered disc fragments and decompress foraminal stenosis [16].

Recently, also another minimally invasive technique, microendoscopic discectomy (MED), has been developed. In MED, a microscope is used and the spine is approached from a posterior direction and not transforaminal. Therefore, this technique is not considered in the current systematic review.

Endoscopic surgery for lumbar disc herniations has been available for more than 30 years, but at present a systematic review of all relevant studies on the effectiveness of transforaminal endoscopic surgery in patients with symptomatic lumbar disc herniations is lacking.

\section{Methods}

\section{Objective}

The objective of this systematic review was to assess the effectiveness of transforaminal endoscopic surgery in patients with symptomatic lumbar disc herniations. The main research questions were

1. What is the effectiveness of transforaminal endoscopic surgery?

a. What is the effectiveness of the older intradiscal transforaminal technique and the more recently developed extracanal transforaminal technique?

b. What is the effectiveness of transforaminal endoscopic surgery for the different types of herniations (mere lateral herniations versus central herniations versus all types of lumbar disc herniations)?

2. What is the effectiveness of transforaminal endoscopic surgery when compared with open microdiscectomy?

For this systematic review, we used the method guidelines for systematic reviews as recommended by the Cochrane Back Review Group [61]. Below the search 
strategy, selection of the studies, data extraction, methodological quality assessment and data analysis are described in more detail. All these steps were performed by two independent reviewers and during consensus meetings potential disagreements between the two reviewers regarding these issues were discussed. If they were not resolved, a third reviewer was consulted.

\section{Search strategy}

An experienced librarian performed a comprehensive systematic literature search. The MEDLINE and EMBASE databases were searched for relevant studies from 1973 to May 2008. The search strategy consisted of a combination of keywords concerning the technical procedure and keywords regarding the anatomical features and pathology (Table 1). We conducted two reviews, one on lumbar disc herniation and one on spinal stenosis, and combined the search strategy for these two reviews for efficiency reasons. These keywords were used as MESH headings and free text words. The full search strategy is available upon request.

\section{Selection of studies}

The search was limited to English, German and Dutch studies, because these are the languages that the review authors are able to read and understand. Two review authors independently examined all titles and abstracts that met our search terms and reviewed full publications, when necessary. In addition, the reference sections of all primary studies were inspected for additional references. Studies were included that describe transforaminal endoscopic surgery for adult patients with symptomatic lumbar disc herniations. As we expected only a limited number of randomized controlled trials in this field, we also included observational studies (non-randomized controlled clinical trials, cohort studies, case-control studies and retrospective

Table 1 Selection of terms used in our search strategy

\begin{tabular}{ll}
\hline Technical procedure & Anatomical features/disorder \\
\hline Endoscopy & Spine \\
Arthroscopy & Back \\
Video-assisted surgery & Back pain \\
$\begin{array}{l}\text { Surgical procedures, minimally } \\
\text { invasive }\end{array}$ & Spinal diseases \\
Microsurgery & Disc displacement \\
Transforaminal & Intervertebral disc \\
& displacement \\
Discectomy & Spinal cord compression \\
Percutaneous & Sciatica \\
Foraminotomy, foraminoplasty & Radiculopathy \\
discoscopy & \\
\hline
\end{tabular}

patient series). To be included, studies had to report on more than 15 cases, with a follow-up period of more than 6 weeks.

\section{Data extraction}

Two review authors independently extracted relevant data from the included studies regarding design, population (e.g. age, gender, duration of complaints before surgery, etc), type of surgery, type of control intervention, follow-up period and outcomes. Primary outcomes that were considered relevant are pain intensity (e.g. visual analogue scale or numerical rating scale), functional status (e.g. Roland Morris Disability Scale, Oswestry Scale), global perceived effect (e.g. McNab score, percentage patients improved), vocational outcomes (e.g. percentage return to work, number of days of sick leave), and other outcomes (recurrences, complication, re-operation and patient satisfaction). We contacted primary authors where necessary for clarification of overlap of data in different articles.

\section{Methodological quality assessment}

Two review authors independently assessed the methodological quality of the included studies. Controlled trials were assessed using a criteria list recommended by the Cochrane Back review group as listed in Table 2 [61]. If studies met at least 6 out of the 11 criteria, the study was considered to have a low risk of bias (RoB). If only 5 or less of the criteria were met, the study was labelled as high RoB Non-controlled studies were assessed using a modified 5-point assessment score as listed in Table 3. Disagreements were resolved in a consensus meeting and a third review author was consulted when necessary.

\section{Data analysis}

To assess the effectiveness of transforaminal endoscopic surgery and to compare it to open microdiscectomy, the results of outcome measures were extracted from the original studies. The outcome data of some studies were recalculated, because the authors of the original papers did not handle drop outs, lost to follow-up and/or failed operations adequately. If a study reported several follow-up intervals, the outcome of the longest follow-up moment was used.

Because only one randomized trial was identified and the controlled trials were heterogeneous regarding study populations, endoscopic techniques, outcome measures, measurement instruments and follow-up moments, statistical pooling was not performed. The median and range (min-max) of the results of the individual studies for each outcome measure are presented. 
Table 2 Criteria list for quality assessment of controlled studies

\begin{tabular}{llll}
\hline $\mathrm{A}$ & Was the method of randomization adequate? & $\mathrm{Y}$ & $\mathrm{N}$ \\
$\mathrm{B}$ & Was the treatment allocation concealed? & $\mathrm{Y}$ & $\mathrm{N}$ \\
$\mathrm{C}$ & Were the groups similar at baseline regarding the most important prognostic indicators? & $\mathrm{Y}$ & $\mathrm{N}$ \\
$\mathrm{D}$ & Was the patient blinded to the intervention? & $\mathrm{Y}$ & $\mathrm{N}$ \\
$\mathrm{E}$ & Was the care provider blinded to the intervention & $\mathrm{Y}$ & $\mathrm{N}$ \\
$\mathrm{F}$ & Was the outcome assessor blinded to the intervention? & $\mathrm{Y}$ & $\mathrm{N}$ \\
$\mathrm{G}$ & Were co-interventions avoided or similar? & $\mathrm{N}$ & $\mathrm{N}$ \\
$\mathrm{H}$ & Was the compliance acceptable in all groups? & $\mathrm{Y}$ & $\mathrm{N}$ \\
$\mathrm{I}$ & Was the drop out rate described and acceptable? & $\mathrm{Y}$ & $\mathrm{N}$ \\
$\mathrm{J}$ & Was the timing of the outcome assessment in all groups similar? & ? \\
$\mathrm{K}$ & Did the analysis include an intention to treat analysis? & $\mathrm{Y}$ & $\mathrm{N}$ \\
\hline
\end{tabular}

? score unclear

A: A random (unpredictable) assignment sequence. Examples of adequate methods are computer generated random number table and use of sealed opaque envelopes. Methods of allocation using date of birth, date of admission, hospital numbers or alternation should not be regarded as appropriate

B: Assignment generated by an independent person not responsible for determining the eligibility of the patients. This person has no information about the persons included in the trial and has no influence on the assignment sequence or on the decision about eligibility of the patient

C: In order to receive a 'yes', groups have to be similar at baseline regarding demographic factors, duration and severity of complaints, percentage of patients with neurological symptoms and value of main outcome measure(s)

D: The reviewer determines if enough information about the blinding is given in order to score a 'yes

E: The reviewer determines if enough information about the blinding is given in order to score a 'yes'

F: The reviewer determines if enough information about the blinding is given in order to score a 'yes'

G: Co-interventions should either be avoided in the trial design or similar between the index and control groups

$\mathrm{H}$ : The reviewer determines if the compliance to the interventions is acceptable, based on the reported intensity, duration, number and frequency of sessions for both the index intervention and control intervention(s)

I: The number of participants who were included in the study but did not complete the observation period or were not included in the analysis must be described and reasons given. If the percentage of withdrawals and drop outs does not exceed $20 \%$ for short-term follow-up and $30 \%$ for long-term follow-up and does not lead to substantial bias a 'yes' is scored. (N.B. these percentages are arbitrary, not supported by literature)

$\mathrm{J}$ : The timing of outcome assessment should be identical for all intervention groups and for all important outcome assessments

$\mathrm{K}$ : All randomized patients are reported/analysed in the group they were allocated to by randomization for the most important moments of effect measurement (minus missing values) irrespective of non-compliance and co-interventions

Table 3 Criteria list for quality assessment of non-controlled studies

\begin{tabular}{llll}
\hline A & Patient selection/inclusion adequately described? & $\mathrm{Y}$ & $\mathrm{N}$ \\
$\mathrm{B}$ & Drop out rate described? & $\mathrm{Y}$ & $\mathrm{N}$ \\
$\mathrm{C}$ & Independent assessor? & $\mathrm{Y}$ & $\mathrm{N}$ \\
$\mathrm{D}$ & Co-interventions described? & $\mathrm{Y}$ & $\mathrm{N}$ \\
$\mathrm{E}$ & Was the timing of the outcome assessment similar? & $\mathrm{Y}$ & $\mathrm{N}$ \\
\hline
\end{tabular}

? score unclear

A: All the basic elements of the study population are adequately described; i.e. demography, type and level of disorder, physical and radiological inclusion and exclusion criteria, pre-operative treatment and duration of disorder

B: Are the patients of whom no outcome was obtained, described in quantity and reason for drop out

C: The data were assessed by an independent assessor

D: All co-interventions in the population during and after the operation are described

E: The timing of outcome assessment should be more or less identical for all intervention groups and for all important outcome assessments

\section{Results}

Search and selection

Two thousand five hundred and thirteen references were identified in MEDLINE and EMBASE that were potentially relevant for the reviews on lumbar disc herniation and spinal stenosis. After checking the titles and abstracts, a total of 123 full text articles were retrieved that were potentially eligible for this review on lumbar disc herniation. Reviewing the reference lists of these articles resulted in an additional 17 studies. Some patient cohorts 
were described in more than one article. In these cases, all articles were used for the quality assessment of the study, but outcome data reporting the longest follow-up was used. After scrutinising all full text papers, 39 studies reported in 45 articles were included in this review. Sixteen studies (41\%) had a mean follow-up of more than 2 years. The characteristics and outcomes of the included studies are presented in Tables 4, 5, 6 and 7.

Type of studies and methodological quality

A total of six prospective controlled studies and two retrospective controlled studies were included. Of the six prospective controlled studies, only the study by Hermantin et al. [11] was considered to have a low RoB. The other five prospective controlled studies and two retrospective controlled were labelled as a high RoB (the full RoB assessment is available upon request).

Furthermore, 12 studies were designed as prospective cohort (without control group) and there were 19 retrospective studies (also without control group). When it was unclear whether the study was prospective or retrospective, the study was considered retrospective.

Of the six prospective controlled studies, four compared transforaminal endoscopic surgery with open discectomy or microdiscectomy. All four were reported as randomized trials, but in three of them the method of randomization was inadequate. Mayer and Brock [39] did not describe the randomization method at all, and Krappel et al. [31] and Ruetten et al. [47] did not randomize, but allocated patients alternately to transforaminal endoscopic surgery or microdiscectomy. Only in the low RoB study by Hermantin et al. [11] randomization was adequately performed in 60 patients with non-sequestered lumbar disc herniations. However, the generalizability of this study is poor because patients with a specific type of herniated disc were selected and results are consequently not directly transferable to all patients with lumbar disc herniations.

\section{Outcomes}

1. What is the effectiveness of transforaminal endoscopic surgery?

No randomized controlled trials were identified. Outcomes of 31 observational, non-controlled studies are presented in Table 8. The median overall improvement of leg pain (VAS) was 88 (range 65-89\%), global perceived effect (MacNab) 85 (72-94\%), return to work of 90\%, recurrence rate $1.7 \%$, complications $2.8 \%$ and re-operations $7 \%$.

1a. What is the effectiveness of the older intradiscal technique and the more recently developed intracanal technique?
No randomized controlled trials were identified. In Table 9 the results of 14 non-controlled studies describing the intradiscal technique and 16 non-controlled studies describing the intracanal technique are presented. The median leg pain improvement (VAS) was $83 \%(78-88 \%)$ for the intradiscal versus $88 \%(65-89 \%)$ for the intracanal technique and the results for global perceived effect were (MacNab) 85\% (78-89\%) versus 86\% (72-93\%), respectively; and other outcomes are listed in Table 9.

1b. What is the effectiveness of transforaminal endoscopic surgery for the different types of herniations (mere lateral herniations versus central herniations versus all types of lumbar disc herniations)?

No randomized controlled trials were identified. Six noncontrolled studies described surgery for far-lateral herniations, one for central herniations and in 15 studies all types of herniations were included. The median GPE (MacNab) was $86 \%(85-86 \%)$ for lateral herniations, $91 \%$ for central herniations and $83 \%$ (79-94\%) for all types of herniations. Other outcomes are listed in Table 10.

2. What is the effectiveness of transforaminal endoscopic surgery compared to open microdiscectomy?

Six controlled studies $(n=720)$ were identified that compared transforaminal endoscopic to open microdiscectomy. Four of them were prospective and two retrospective studies.

Only one randomized controlled trial $(n=60)$ with a low RoB was identified that compared pure intradiscal technique with open laminotomy [11]. There were no statistically significant differences between the two groups. The pain reduction in the transforaminal endoscopic surgery group was 71 versus $82 \%$ in the open laminotomy group after on average 32 months follow-up. The overall improvement was 97 versus $93 \%$, re-operation rate 6.7 versus $3.3 \%$ and complication rate 6.7 versus $0 \%$, respectively. Overall, the controlled studies found no differences in outcomes: leg pain reduction in the transforaminal endoscopic surgery group was 89 versus $87 \%$ in the open microdiscectomy group, overall improvement (GPE) was 84 versus $78 \%$, re-operation rate 6.8 versus $4.7 \%$ and complication rate 1.5 versus $1.0 \%$, respectively (Table 11 ). In none of the studies, there were any statistically significant differences between the intervention groups on pain improvement and global perceived effect. Ruetten et al. [47] ( $n=200)$ reported statistically significant differences on return to work, but this was a secondary outcome and it was unclear how many subjects in each group had work and if groups were comparable regarding work status and history of work absenteeism at baseline.

In one study, transforaminal endoscopic surgery was compared with the same operation combined with 


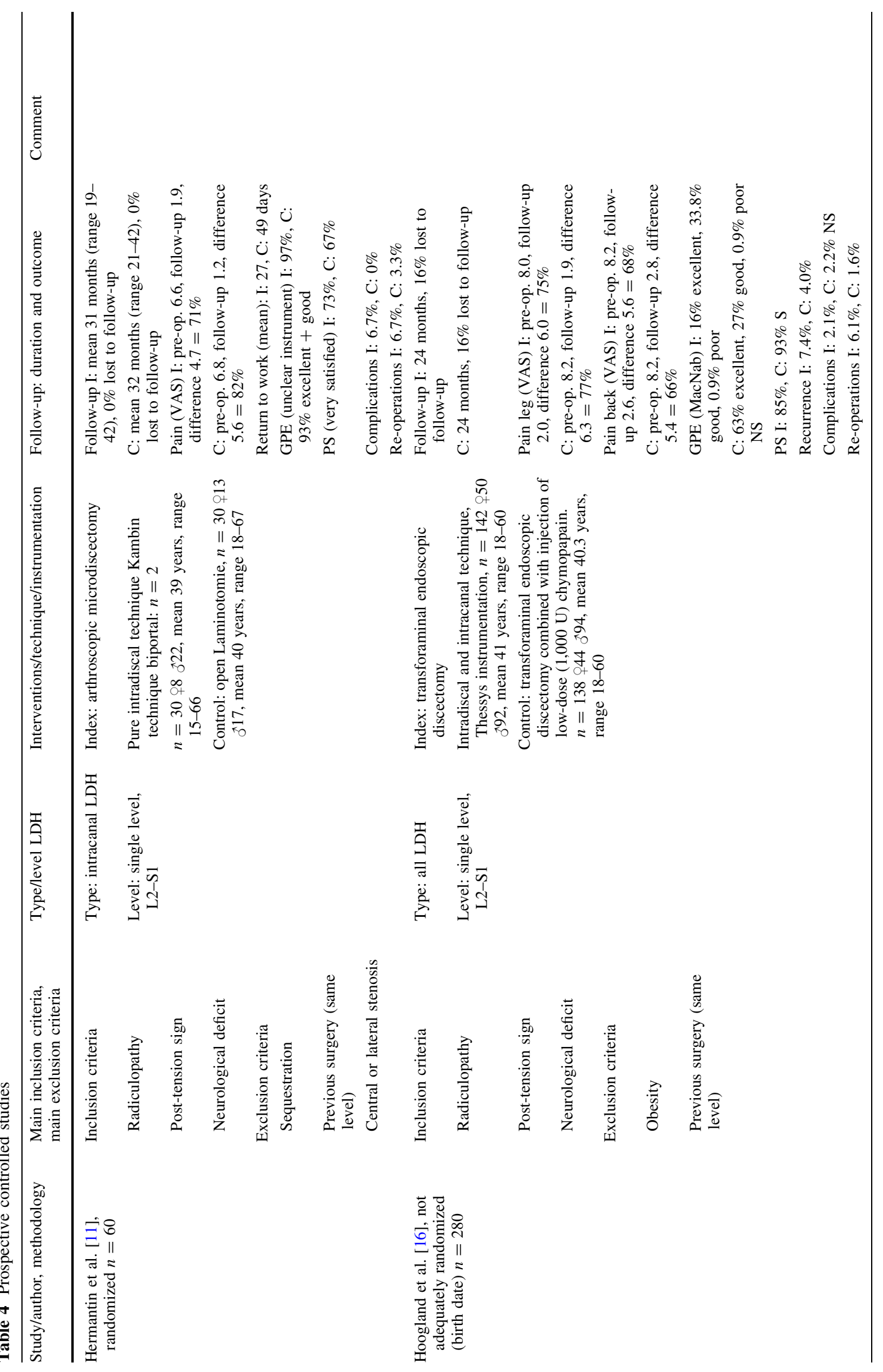




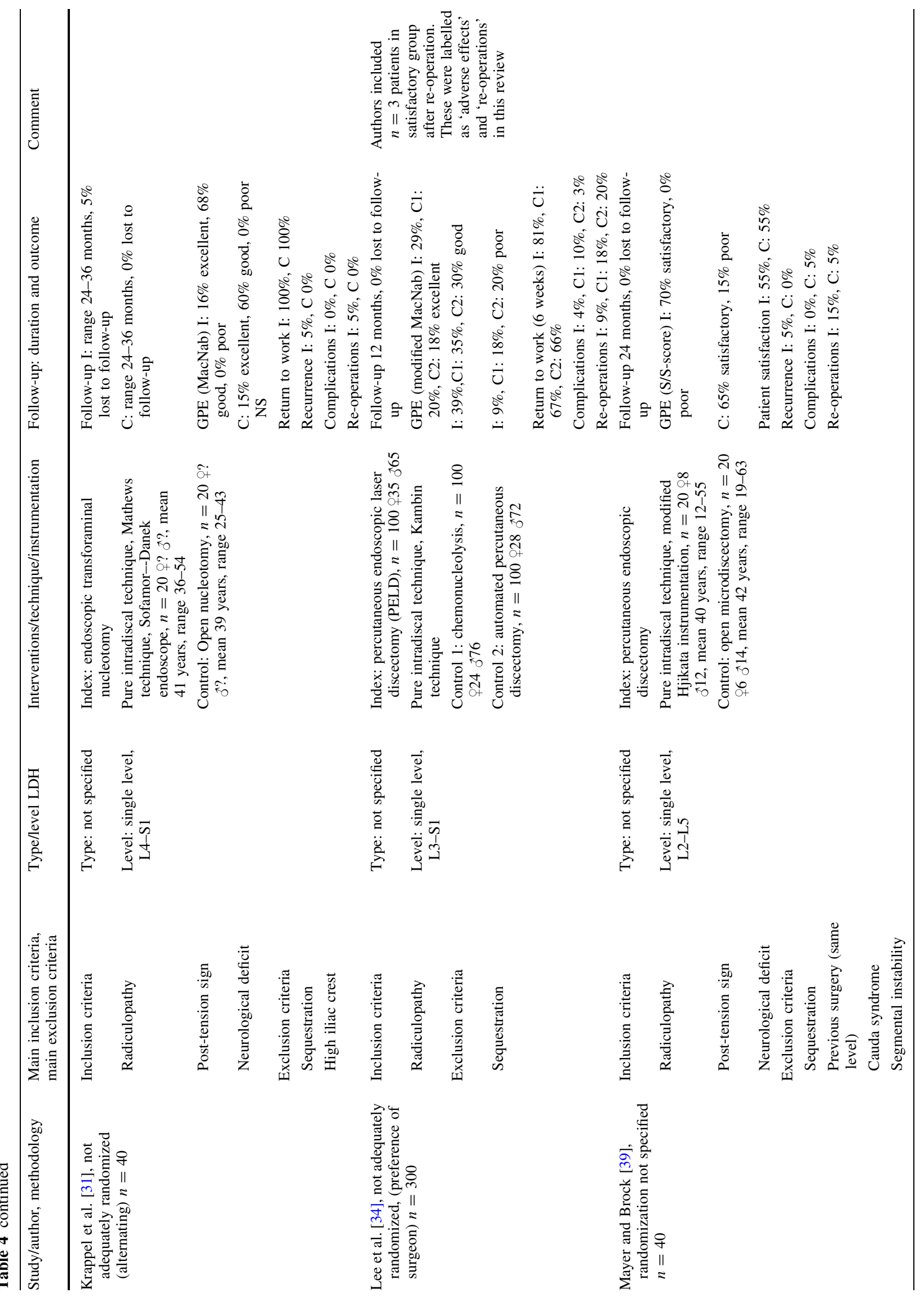




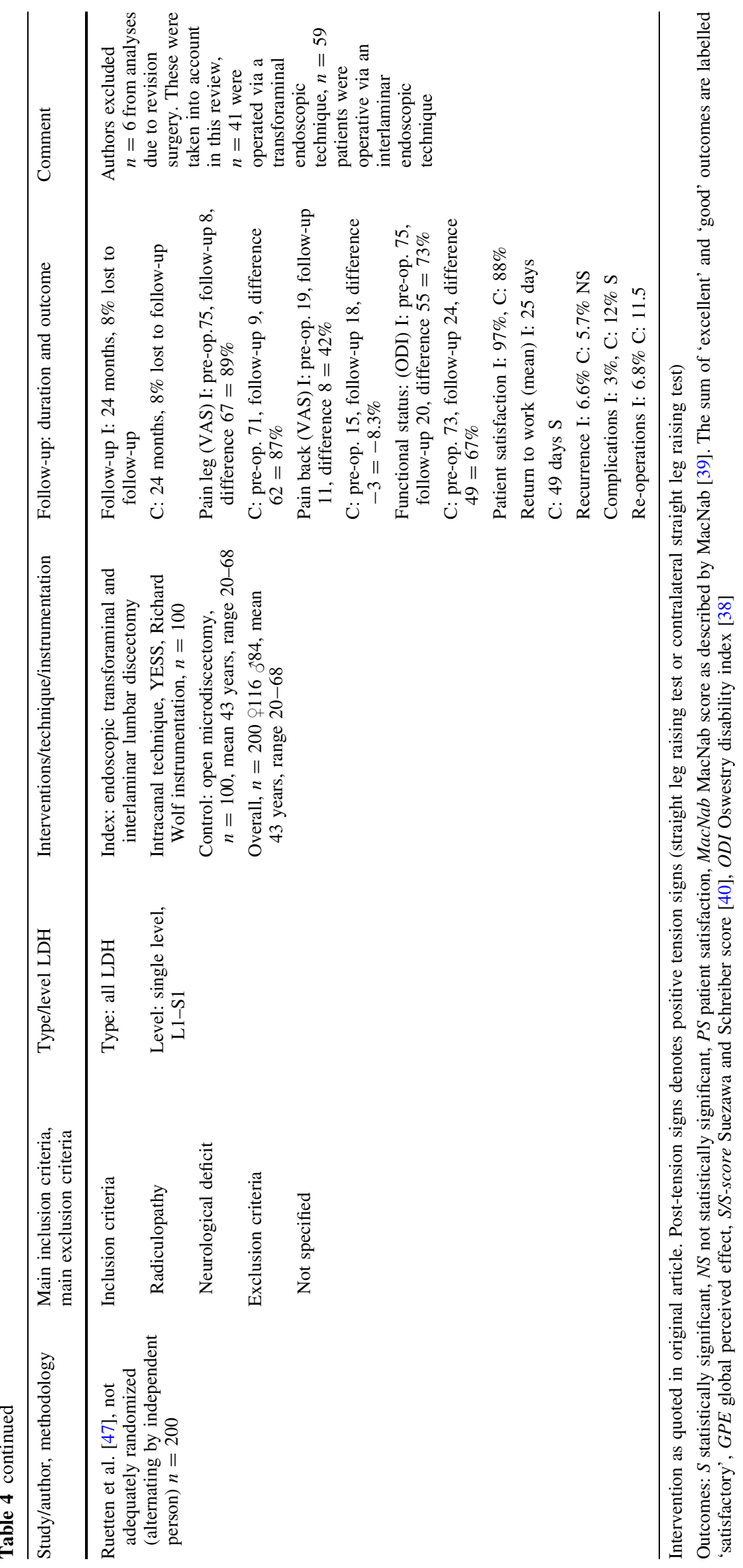




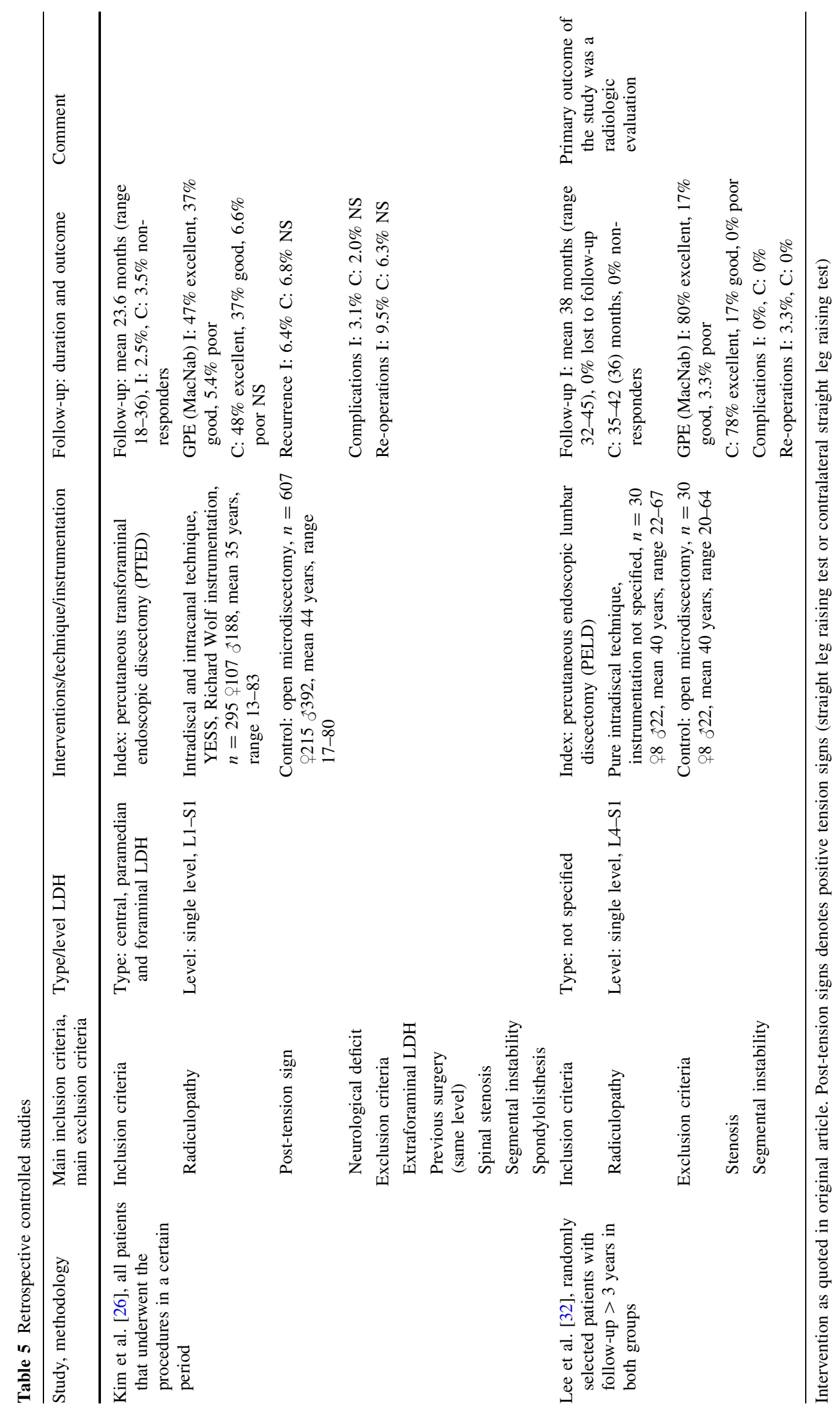




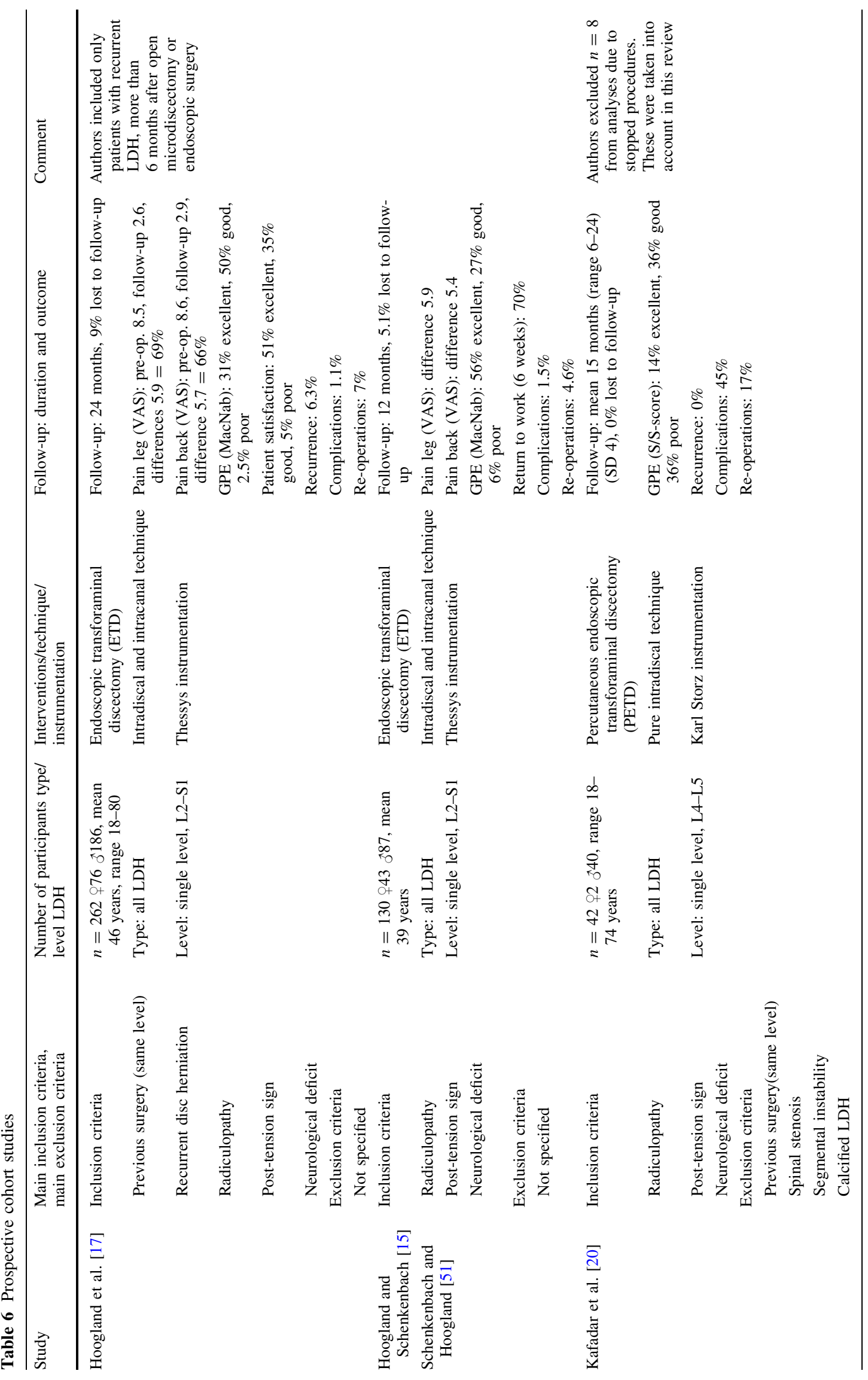




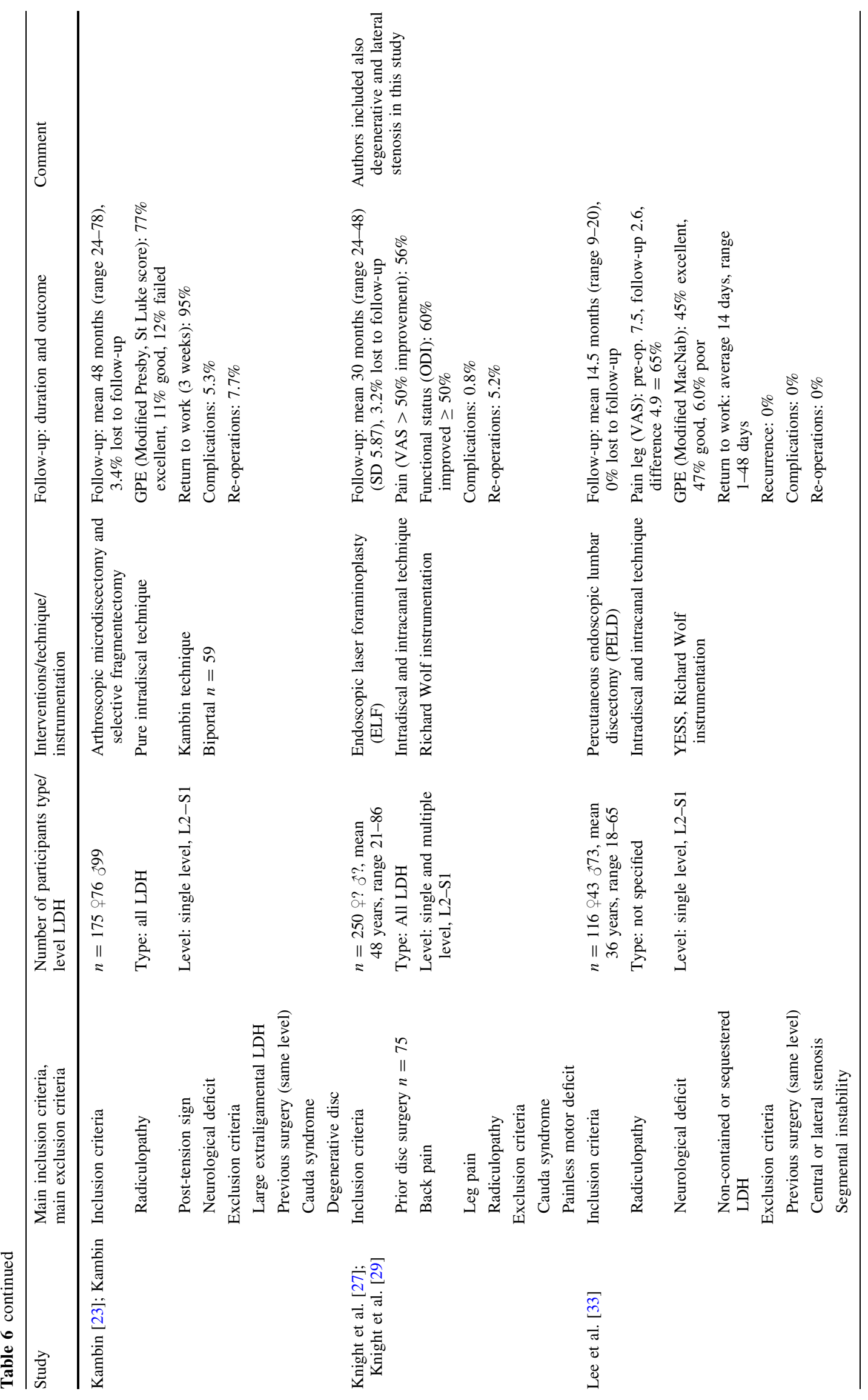




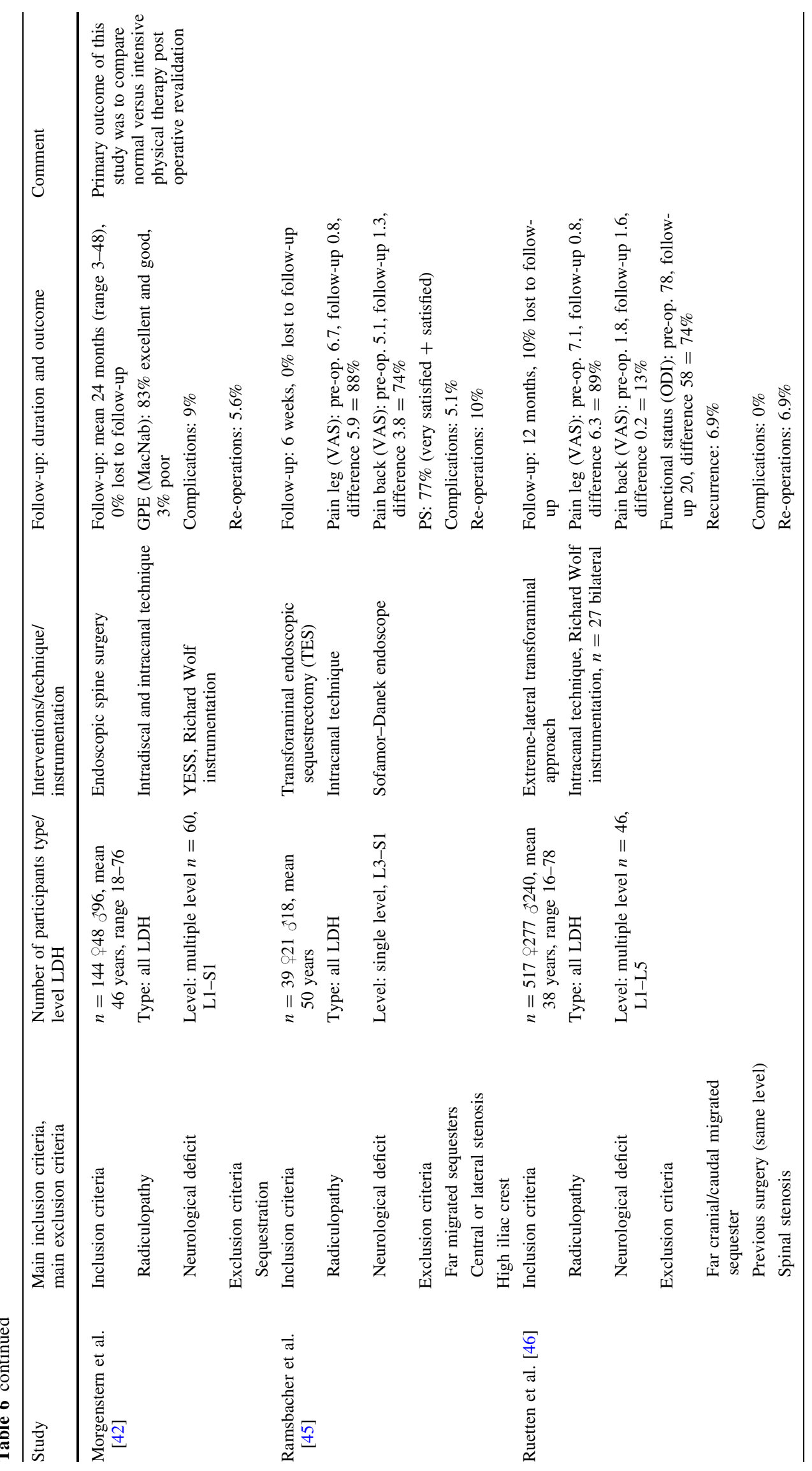




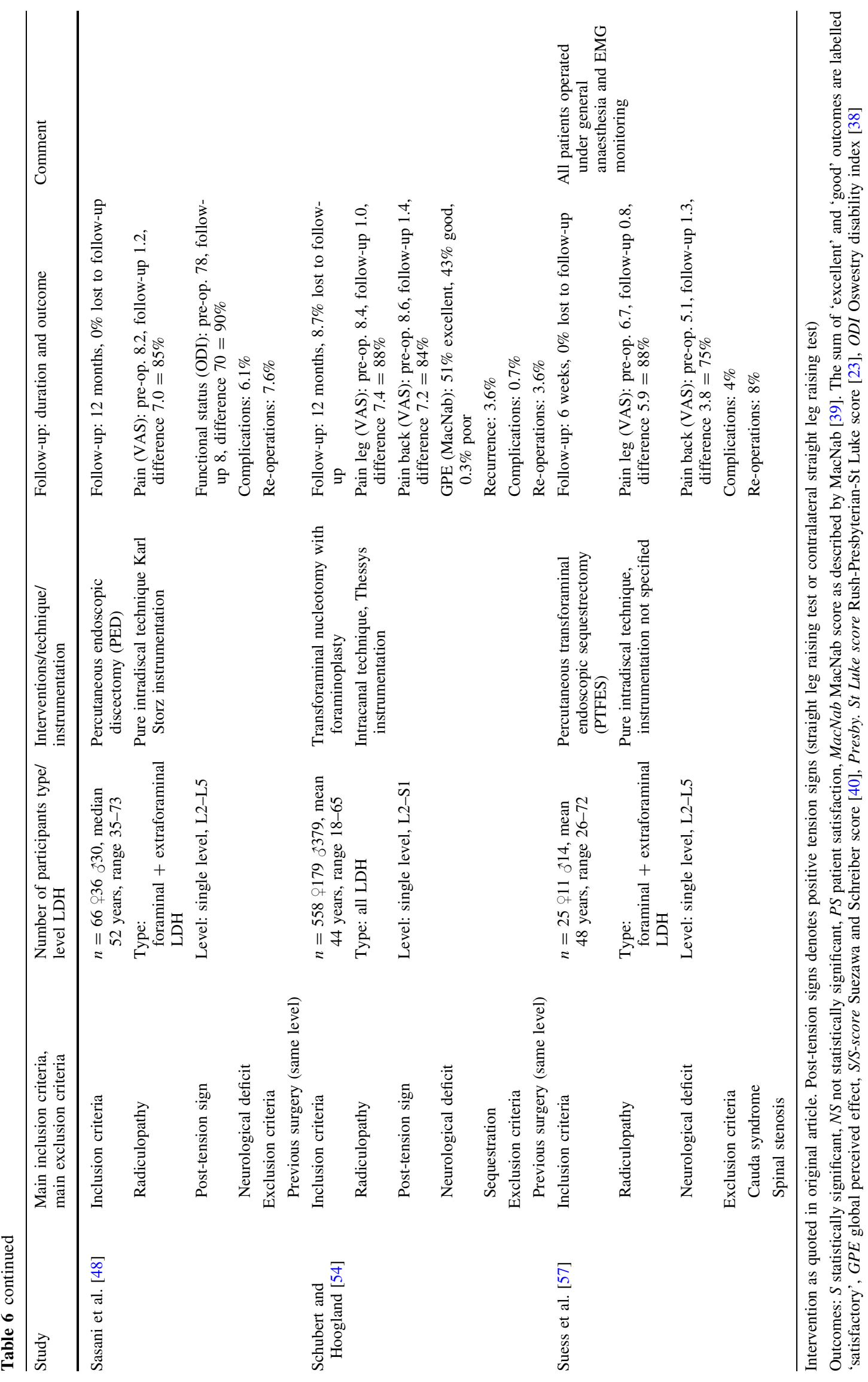




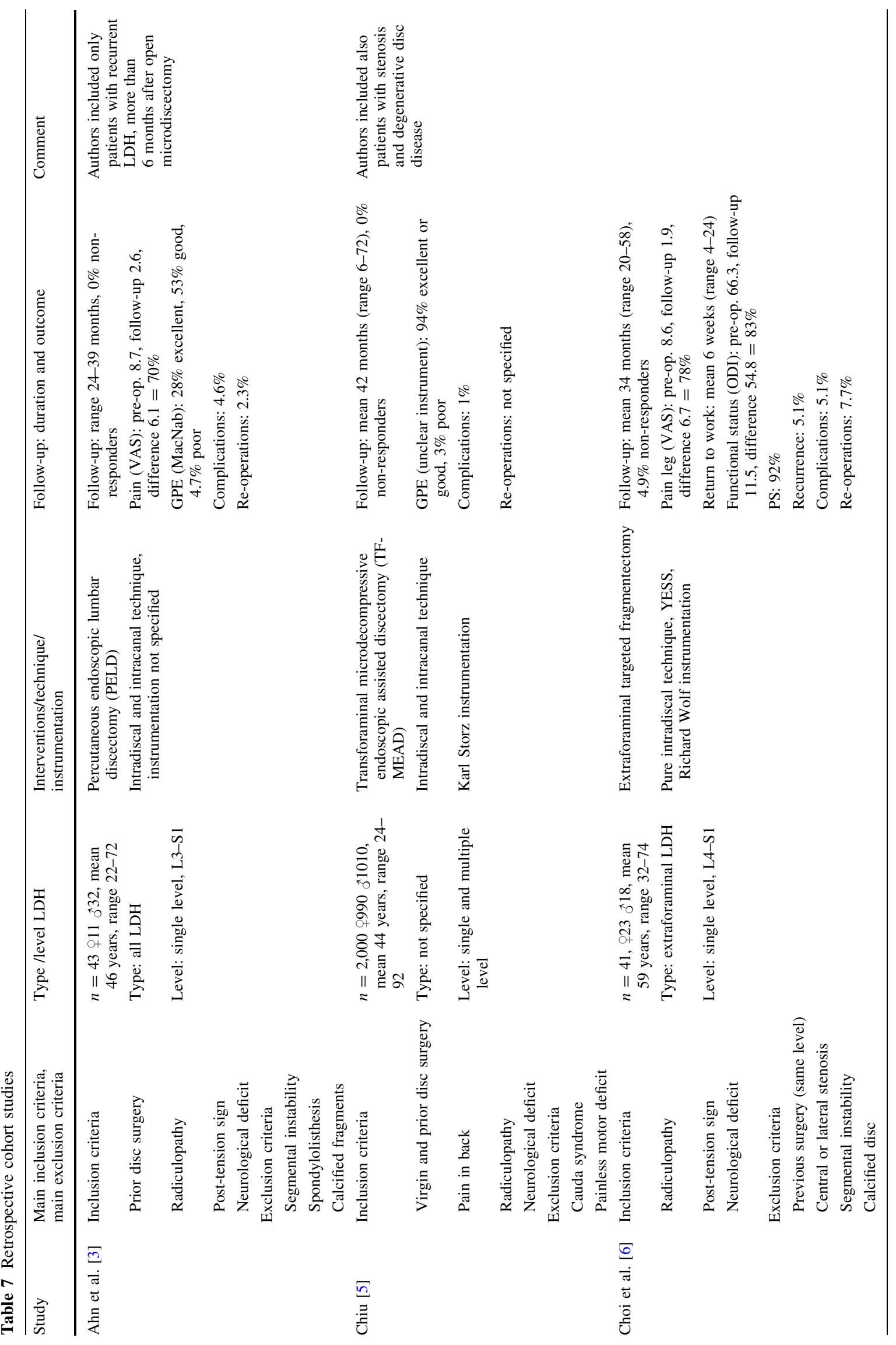




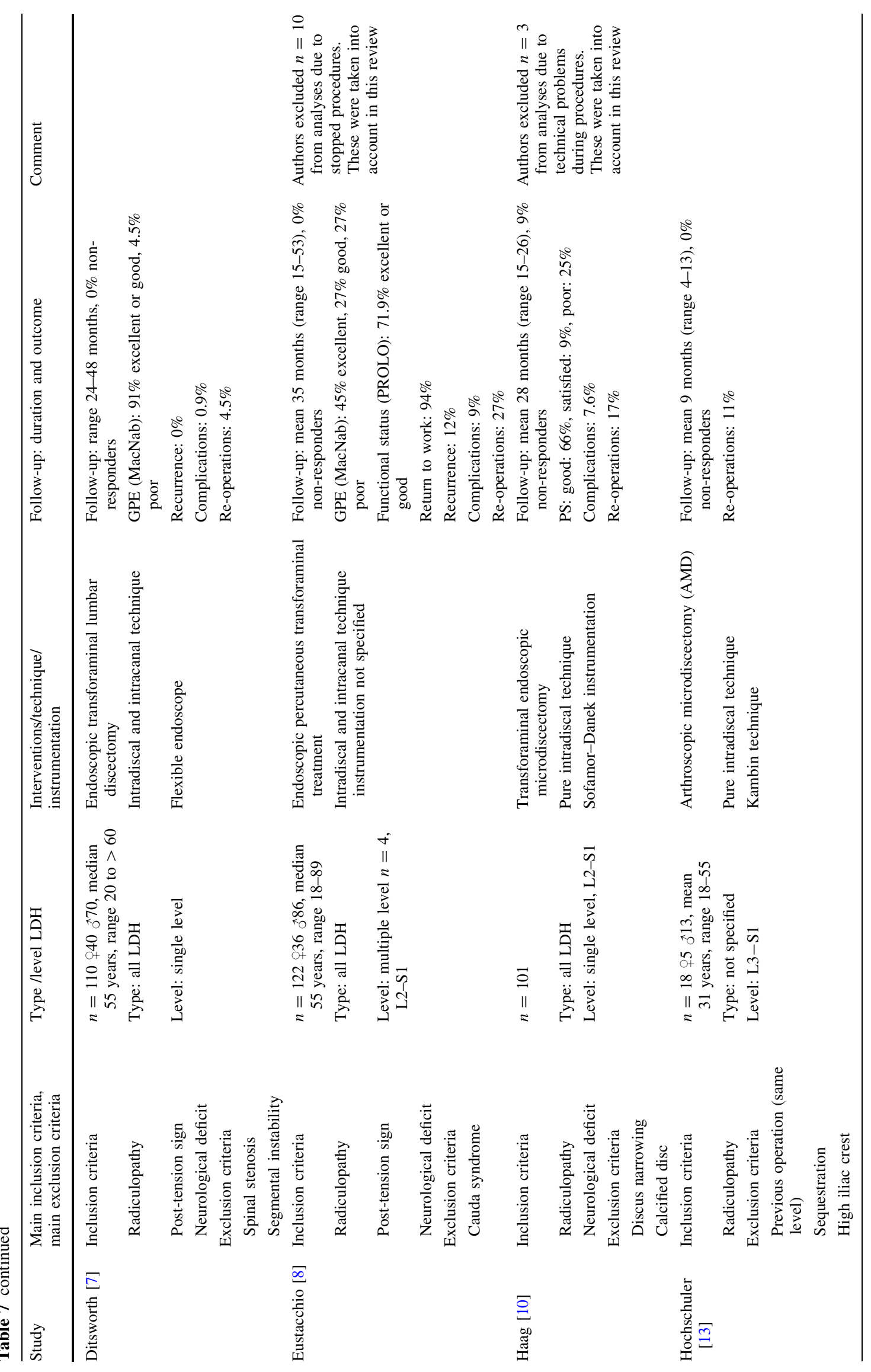




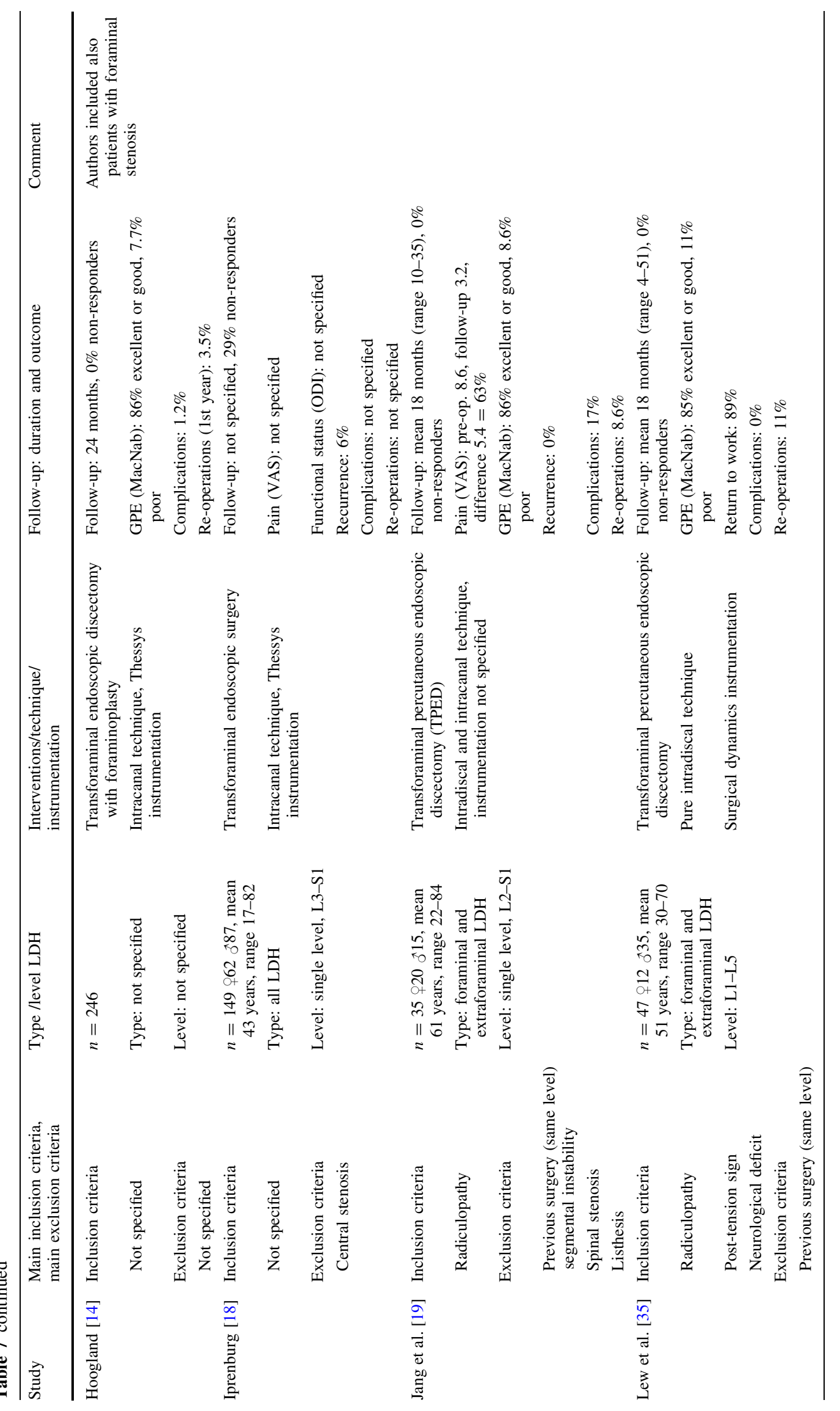




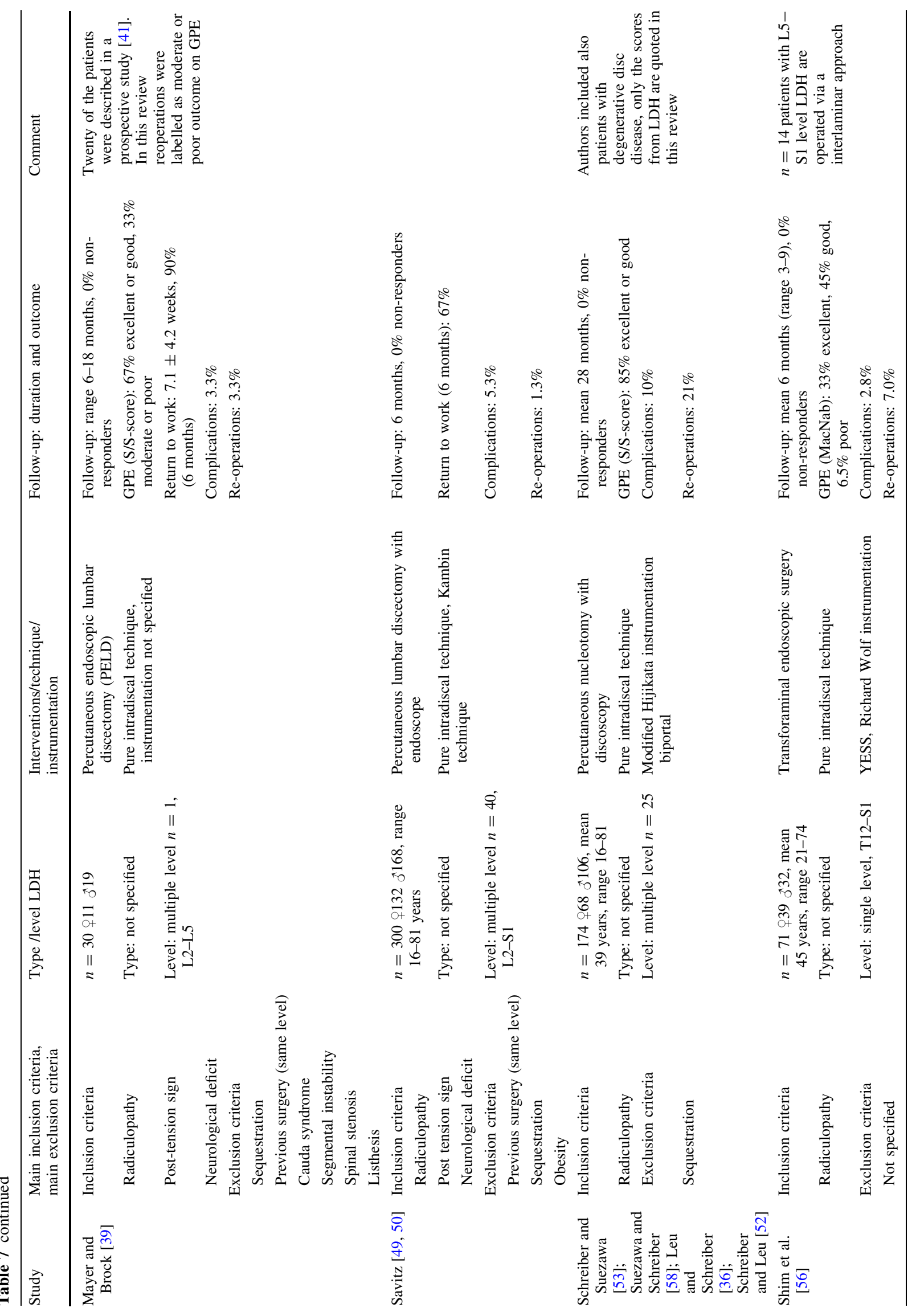




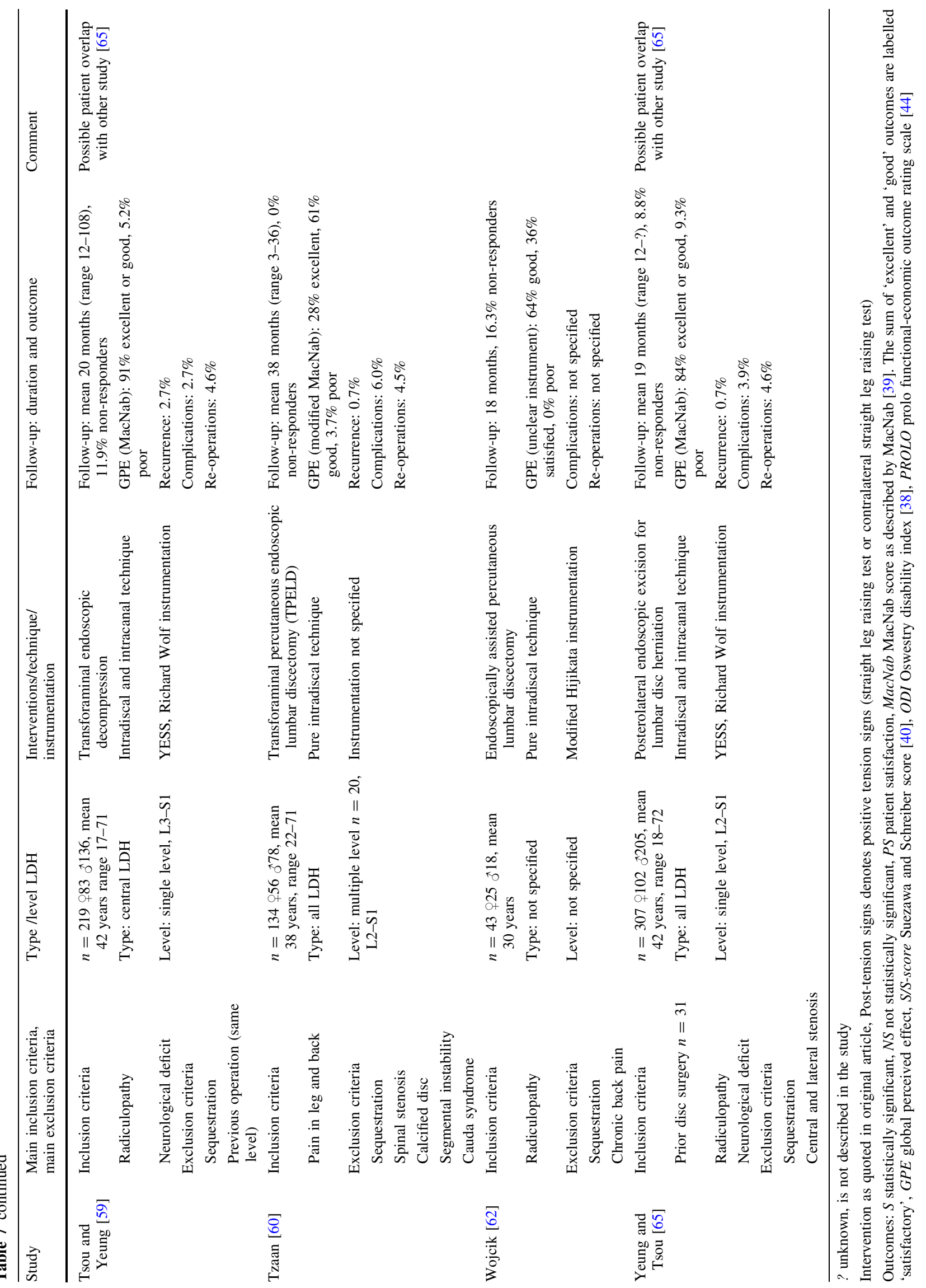


Table 8 Overall outcome, noncontrolled studies
Outcomes: MacNab MacNab score as described by MacNab [39]. The sum of 'excellent' and 'good' outcomes are labelled 'satisfactory', GPE global perceived effect, ODI Oswestry disability index [38]

Table 9 Intradiscal and intracanal techniques, outcomes non-controlled studies
Outcomes: MacNab MacNab score as described by MacNab [39]. The sum of 'excellent' and 'good' outcomes are labelled 'satisfactory', GPE global perceived effect

\begin{tabular}{lll}
\hline Outcome measure (instrument) & Studies (patients) & Outcome median (min-max) \\
\hline Pain leg (VAS) & $7(n=1,558)$ & $88 \%(65-89 \%)$ improvement \\
Pain back (VAS) & $5(n=1,401)$ & $74 \%(13-84 \%)$ improvement \\
Pain (region not specified) (VAS) & $3(n=144)$ & $70 \%(63-85 \%)$ improvement \\
GPE (MacNab) & $15(n=2,544)$ & $85 \%(72-94 \%)$ satisfactory \\
& & $6 \%(0.3-27 \%)$ poor \\
Functional status (ODI) & $3(n=624)$ & $83 \%(74-90 \%)$ improvement \\
Patient satisfaction & $3(n=181)$ & $78 \%(75-92 \%)$ satisfactory \\
Return to work & $5(n=757)$ & $90 \%(67-95 \%)$ \\
Recurrence & $13(n=2,612)$ & $1.7 \%(0-12 \%)$ \\
Complication & $28(n=6,336)$ & $2.8 \%(0-40 \%)$ \\
Re-operation & $28(n=4,135)$ & $7 \%(0-27 \%)$ \\
\hline
\end{tabular}

\begin{tabular}{lll}
\hline Outcome measure (instrument) & Studies & Outcome median (min-max) \\
\hline Pure intradiscal technique 14 studies $(n=1,267)$ intradiscal technique & \\
Pain leg (VAS) & $2(n=66)$ & $83 \%(78-88 \%)$ improvement \\
Pain back (VAS) & $1(n=25)$ & $75 \%$ improvement \\
Pain (region not specified) (VAS) & $1(n=66)$ & $85 \%$ improvement \\
GPE (MacNab) & $3(n=279)$ & $85 \%(78-89 \%)$ satisfactory \\
& & $6.5 \%(3.7-11 \%)$ poor \\
Recurrence & $3(n=217)$ & $0.7 \%(0-5.1 \%)$ \\
Complication & $12(n=1,206)$ & $5.3 \%(0-40 \%)$ \\
Re-operation & $14(n=1,267)$ & $7.5 \%(1.3-30 \%)$ \\
Intracanal technique 16 studies $(n=4,985)$ & & \\
Pain leg (VAS) & $5(n=1,524)$ & $88 \%(65-89 \%)$ improvement \\
Pain back (VAS) & $4(n=1,408)$ & $70 \%(13-84 \%)$ improvement \\
Pain (region not specified) (VAS) & $2(n=78)$ & $67 \%(63-70 \%)$ improvement \\
GPE (MacNab) & $12(n=2,292)$ & $86 \%(72-93 \%)$ satisfactory \\
& & $6 \%(0.3-9.3 \%)$ poor \\
Recurrence & $10(n=2,395)$ & $3.2 \%(0-12 \%)$ \\
Complication & $17(n=5,362)$ & $2.1 \%(0-17 \%)$ \\
Re-operation & $15(n=3,098)$ & $4.6 \%(0-27 \%)$ \\
\hline
\end{tabular}

chymopapain, and one study compared endoscopic surgery with chemonucleolysis and automated discectomy (Table 4).

\section{Discussion}

In the current review, all available evidence regarding the effectiveness of transforaminal endoscopic surgery was identified and systematically summarized. We identified 1 randomized controlled trial, 7 non-randomized controlled trials and 31 observational studies. The methodological quality of these studies was poor. The eight trials did not find any statistically significant differences in leg pain reduction between the transforaminal endoscopic surgery group (89\%) and the open microdiscectomy group (87\%); overall improvement ( 84 vs. $78 \%$ ), re-operation rate $(6.8$ vs. $4.7 \%)$ and complication rate (1.5 vs. $1 \%$ ), respectively. We conclude that current evidence on the effectiveness of transforaminal endoscopic surgery is poor and does not provide valid information to either support or refute using this type of surgery in patients with symptomatic lumbar disc herniations. High-quality randomized controlled trials with sufficiently large sample sizes are direly needed.

This study has a number of limitations that should be considered when drawing conclusions regarding the effectiveness of transforaminal endoscopic surgery for lumbar disc herniations. The included studies in this review were heterogeneous with regard to the selection of patients, the indications for surgery, the surgical techniques used 
Table 10 Outcomes of improvement in lateral herniations, central herniations and all types of herniations

\begin{tabular}{|c|c|c|}
\hline Outcome measure (instrument) & Studies & Outcome median $(\min -\max )$ \\
\hline \multicolumn{3}{|c|}{ Type: far-lateral LDH 6 studies $(n=214)$} \\
\hline Pain (region not specified) (VAS) & $4(n=167)$ & $82 \%(63-88 \%)$ improvement \\
\hline GPE (MacNab) & $2(n=52)$ & $\begin{array}{l}86 \%(85-86 \%) \text { satisfactory } \\
9.8 \%(8.6-11 \%) \text { poor }\end{array}$ \\
\hline \multicolumn{3}{|l|}{ Functional status (ODI) } \\
\hline Recurrence & $2(n=76)$ & $2.6 \%(0-5.1 \%)$ \\
\hline Complication & $5(n=214)$ & $5.1 \%(0-17 \%)$ \\
\hline Re-operation & $5(n=214)$ & $8.0 \%(7.6-11 \%)$ \\
\hline \multicolumn{3}{|l|}{ Type: central LDH 1 study $(n=71)$} \\
\hline GPE (MacNab) & $1(n=71)$ & $\begin{array}{l}91 \% \text { satisfactory } \\
12 \% \text { poor }\end{array}$ \\
\hline Complication & $1(n=71)$ & $2.7 \%$ \\
\hline Re-operation & $1(n=71)$ & $4.6 \%$ \\
\hline \multicolumn{3}{|l|}{ Type: all LDH 15 studies $(n=3,067)$} \\
\hline Pain leg (VAS) & $4(n=1,374)$ & $88 \%(69-89 \%)$ improvement \\
\hline Pain back (VAS) & $4(n=1,374)$ & $70 \%(13-84 \%)$ improvement \\
\hline Pain (region not specified) (VAS) & $1(n=43)$ & $70 \%$ improvement \\
\hline GPE (MacNab) & $9(n=1,810)$ & $\begin{array}{l}83 \%(79-94 \%) \text { satisfactory } \\
4.6 \%(0.3-9.3 \%) \text { poor }\end{array}$ \\
\hline Recurrence & $9(n=2,201)$ & $3.6 \%(0-12 \%)$ \\
\hline Complication & $15(n=2,934)$ & $4.9 \%(0-45 \%)$ \\
\hline Re-operation & $15(n=2,934)$ & $5.6 \%(2.3-27 \%)$ \\
\hline
\end{tabular}

$L D H$ lumbar disc herniation, Type in transversal section, subdivided in central, paramedian, foraminal and extraforaminal herniations

Table 11 Outcomes of improvement of transforaminal endoscopic versus open microdiscectomy
$I$ index intervention, $C$ control intervention

\begin{tabular}{|c|c|c|}
\hline Outcome measure (instrument) & Studies & Outcome median (min-max) \\
\hline \multicolumn{3}{|c|}{ Endoscopic (index) versus open microdiscectomy (control) } \\
\hline Pain leg (VAS) & $1(n=200)$ & $\begin{array}{l}\text { Index } 89 \% \text { improvement } \\
\text { Control } 87 \% \text { improvement }\end{array}$ \\
\hline Pain back (VAS) & $1(n=200)$ & $\begin{array}{l}\text { Index } 42 \% \text { improvement } \\
\text { Control }-8.3 \% \text { improvement }\end{array}$ \\
\hline Pain (region not specified) (VAS) & $1(n=60)$ & $\begin{array}{l}\text { Index } 71 \% \text { improvement } \\
\text { Control } 82 \% \text { improvement }\end{array}$ \\
\hline GPE (MacNab/other) & $5(n=1,102)$ & $\begin{array}{l}\text { Index } 84 \%(70-97 \%) \text { satisfactory } \\
1.7 \%(0-5.4 \%) \text { poor } \\
\text { Control } 78 \%(65-93 \%) \text { satisfactory } \\
3.3 \%(0-15 \%) \text { poor }\end{array}$ \\
\hline Recurrences & $4(n=1,182)$ & $\begin{array}{l}\text { Index } 5.7 \%(5-6.6 \%) \\
\text { Control } 2.9 \%(0-6.8 \%)\end{array}$ \\
\hline Complications & $6(n=1,302)$ & $\begin{array}{l}\text { Index } 1.5 \%(0-6.7 \%) \\
\text { Control } 1.0 \%(0-12 \%)\end{array}$ \\
\hline Re-operations & $6(n=1,302)$ & $\begin{array}{l}\text { Index } 6.8 \%(3.3-15 \%) \\
\text { Control } 4.7 \%(0-11.5 \%)\end{array}$ \\
\hline
\end{tabular}

and the duration of follow-up. Furthermore, different outcome measures were used in the studies and different instruments used for the same outcomes. Below we will elaborate on the most important sources of heterogeneity in more detail.

\section{Selection of patients}

Patient selection and in/exclusion criteria were often not clearly described. Amongst others, this includes physical examinations, radiological findings, the period and type 
of pre-operative therapies and duration of symptoms. In most studies, patients received some type of preoperative conservative treatment for a few months, but the exact content of the conservative treatment was not specified. Also, duration of symptoms before surgery differed amongst studies and in some studies patients with acute onset ( $<2$ weeks) of complaints were also included. In some studies only 'virgin discs' were included, whilst in others a previous disc operation was not an exclusion criterion or it was not mentioned if patients with a previous disc operation were excluded or not. In two studies only recurrent herniations after open microdiscectomy were treated with transforaminal endoscopic surgery [3, 17]. Some studies included only lateral or central herniations, whereas others included all herniations. Given this, there is much heterogeneity in patient selection between the studies which hinders comparability between studies.

\section{Techniques}

Indications for endoscopic surgery have changed over time with the introduction of new techniques, scopes and instruments. Initially non-contained, sequestered and central herniations were exclusion criteria for endoscopic surgery and L5-S1 level herniations were not always possible to reach as the diameter of the foramen intervertebral decreases in the lumbar area from cranial to caudal [46]. In the earlier studies of transforaminal endoscopic surgery, discectomy was performed through a fenestration in the lateral annulus and the focus was limited on central debulking and reduction in intradiscal pressure. Later studies described that the hernia was extracted from the spinal canal with or without an intradiscal debulking. We found comparable outcomes for these intradiscal and intracanal techniques. However, one could debate whether these procedures are really two different techniques. The main distinction is a $10^{\circ}$ difference in direction and may be within the limits of measurement error and anatomical variation. Far-lateral herniations occur in $3-11 \%$ of lumbar disc herniations and usually cause severe sciatic pain [1, 2, 43, 44]. Some reports mentioned more difficulty to assess an extraforaminal herniated lumbar disc through an open procedure and it is often associated with the substantial bone removal [35]. Because transforaminal endoscopic surgery is a posterolateral approach to the spine, lateral herniations might be more easily reached [60]. With lateral herniations, the angle of the instruments should be steeper and, thus, the insertion closer to the midline [6, 19]. We compared the effect of transforaminal endoscopic surgery for lateral herniations with central and all herniations. All outcomes were comparable.
Methodological quality

Most studies had major design weaknesses and the quality of the identified studies was poor, indicating that studies had a high RoB. Only one adequately randomized controlled trial was identified. In most studies, randomization was not performed at all, not performed adequately or not described adequately. Obviously, patients and surgeons cannot be blinded for the surgical intervention. However, many other important quality items were also not met by the majority of studies. Although transforaminal endoscopic surgery for lumbar disc herniation was introduced about 30 years ago and many patients have undergone this intervention since its introduction, only one randomized controlled trial with a low RoB has been published. Only high-quality, randomized controlled trials with sufficiently large sample sizes comparing transforaminal endoscopic surgery to other surgical techniques for lumbar disc herniations can provide strong evidence regarding its effectiveness. Preferably, these trials should be conducted by independent research institutes.

\section{Outcome measures}

The most frequently used outcome measures in the included studies are the VAS score for pain and the MacNab score for global perceived effect. To compare the VAS scores across studies, we calculated the percentage of improvement between the postoperative and preoperative scores. The MacNab score is a 4-point scale ranging from 1 (excellent); 2 (good), 3 (fair) to 4 (poor). In most studies 'excellent' and 'good' were combined and labelled 'satisfactory'. Although a close inspection of the score 'good' on the MacNab, reveals that patients still have occasionally ongoing symptoms, sufficient to interfere with normal work or capacity to enjoy leisure activities [37]. We considered labelling this as a 'satisfactory' outcome was somewhat too positive. Therefore, whenever possible, we presented the original MacNab scores. Although some studies used validated outcomes (e.g. the Oswestry Disability Questionnaire for low back pain-specific functional disability) others used non-validated outcomes, or did not describe at all how disability and improvement were measured. Future trials should use valid and reliable instruments to measure the primary outcomes.

\section{Adverse effects}

\section{Recurrences}

Eighteen studies reported recurrence rates of lumbar disc herniations, but the definition of recurrence varied. In 
this review, we defined a recurrence as a re-appearance of a symptomatic lumbar disc herniation at the same level after a pain-free interval of longer than a month. When in a study the symptomatic hernia appeared within a month, we considered it a recurrence. The median recurrence rate of included studies was $1.7 \%$ (range 0$12 \%$ ). The reported recurrence rate in the literature of open microdiscectomy is similar with reported ranges from 5 to $11 \%$ [60]. The controlled studies found no significant difference in recurrences between the two techniques.

\section{Re-operation}

In the observational studies, the median re-operation rate was $7 \%(0-27 \%)$. The controlled studies found no significant differences in re-operation percentages between endoscopic transforaminal surgery and open microdiscectomy (6.8 vs. $4.7 \%)$. As in most surgical interventions, adequate patient selection and accurate diagnosis seem very important. Most common cause for re-operations was persistent complaints due to missed lateral bony stenosis and remnant fragments [23].

\section{Complications}

One of the suggested advantages of transforaminal endoscopic surgery compared with open microdiscectomy is a lower complication rate [28]. Because of the small incision and minimal internal tissue damage, the revalidation period is supposed to be shorter and scar tissue minimised [29]. In the current review, we found no severe neurological injury and a mean percentage of complications after transforaminal endoscopic surgery of $2.8 \%$. There were no substantial differences in serious complications between endoscopic surgery and open microdiscectomy. Most reported complications were transient dysaesthesia or hypaesthesia. However, it has to be noted that none of the included studies was specifically designed for the assessment of adverse effects, and, therefore, these results have to be interpreted cautiously; also, disadvantages have been reported. Transforaminal endoscopic surgery has a steep learning curve that requires patience and experience, especially for those unfamiliar with percutaneous techniques. In some studies, the patients operated at the beginning of the learning curve had worse outcome [10, 20, 26, 56, 60]. Some patients may experience local anaesthesia as a disadvantage. In three studies, the operations were performed under general anaesthesia [47, 48, 57]. Comprehensive preoperative information about the intervention and permanent communication and constant observation during the operation is of major importance.

\section{Future research}

Only randomized controlled trials that are adequately designed, conducted and reported and that have a low RoB will provide sufficient evidence regarding the effectiveness of transforaminal endoscopic surgery for lumbar disk herniation. High-quality, randomized controlled trials with sufficiently large sample sizes that compare the effectiveness of transforaminal endoscopic surgery with open microdiscectomy for lumbar disc herniations are needed. The short hospital stay, shorter revalidation period and earlier return to work may result in an economic advantage, although this has never been evaluated. Economic evaluations should be performed alongside these trials to assess the cost-effectiveness and cost utility of transforaminal endoscopic surgery.

\section{Conclusion}

This systematic review assessed the effectiveness of transforaminal endoscopic surgery. Of the 39 studies included in this review, most studies had major design weaknesses and were considered having a high RoB. Only one randomized controlled trial was identified, but this trial had poor generalizability. No significant differences in pain, overall improvement, patient satisfaction, recurrence rate, complications and re-operations were found between transforaminal endoscopic surgery and open microdiscectomy. Current evidence on the effectiveness of transforaminal endoscopic surgery is poor and does not provide valid information to either support or refute using this type of surgery in patients with symptomatic lumbar disc herniations.

Conflict of interest statement For this review the authors received a grant from The Health Care Insurance Board (CVZ), Diemen, The Netherlands.

Open Access This article is distributed under the terms of the Creative Commons Attribution Noncommercial License which permits any noncommercial use, distribution, and reproduction in any medium, provided the original author(s) and source are credited.

\section{References}

1. Abdullah AF, Ditto EW III, Byrd EB et al (1974) Extreme-lateral lumbar disc herniations. Clinical syndrome and special problems of diagnosis. J Neurosurg 41:229-234

2. Abdullah AF, Wolber PG, Warfield JR et al (1988) Surgical management of extreme lateral lumbar disc herniations: review of 138 cases. Neurosurgery 22:648-653

3. Ahn Y, Lee SH, Park WM et al (2004) Percutaneous endoscopic lumbar discectomy for recurrent disc herniation: surgical 
technique, outcome, and prognostic factors of 43 consecutive cases. Spine 29:E326-E332

4. Caspar W (1977) A new surgical procedure for lumbar disk herniation causing less tissue damage through a microsurgical approach. Adv Neurosurg 4:74-77

5. Chiu JC (2004) Evolving transforaminal endoscopic microdecompression for herniated lumbar discs and spinal stenosis. Surg Technol Int 13:276-286

6. Choi G, Lee SH, Bhanot A et al (2007) Percutaneous endoscopic discectomy for extraforaminal lumbar disc herniations: extraforaminal targeted fragmentectomy technique using working channel endoscope. Spine 32:E93-E99

7. Ditsworth DA (1998) Endoscopic transforaminal lumbar discectomy and reconfiguration: a posterolateral approach into the spinal canal. Surg Neurol 49:588-597

8. Eustacchio S, Flaschka G, Trummer M et al (2002) Endoscopic percutaneous transforaminal treatment for herniated lumbar discs. Acta Neurochir (Wien) 144:997-1004

9. Forst R, Hausmann B (1983) Nucleoscopy-a new examination technique. Arch Orthop Trauma Surg 101:219-221

10. Haag M (1999) Transforaminal endoscopic microdiscectomy. Indications and short-term to intermediate-term results. Orthopade 28:615-621

11. Hermantin FU, Peters T, Quartararo L et al (1999) A prospective, randomized study comparing the results of open discectomy with those of video-assisted arthroscopic microdiscectomy. J Bone Joint Surg Am 81:958-965

12. Hijikata S (1989) Percutaneous nucleotomy. A new concept technique and 12 years' experience. Clin Orthop Relat Res 238:9-23

13. Hochschuler SH (1991) Posterior lateral arthroscopic microdiskectomy. Semin Orthop 6:113-114

14. Hoogland T (2003) Transforaminal endoscopic discectomy with forminoplasty for lumbar disc herniation. Surg Tech Orthop 1-6

15. Hoogland T, Scheckenbach C (1998) Die endoskopische transforminale diskektomie bei lumbalen bandscheibenforfallen. Orthop Prax 34:352-355

16. Hoogland T, Schubert M, Miklitz B et al (2006) Transforaminal posterolateral endoscopic discectomy with or without the combination of a low-dose chymopapain: a prospective randomized study in 280 consecutive cases. Spine 31:E890-E897

17. Hoogland T, van den Brekel-Dijkstra K, Schubert M et al (2008) Endoscopic transforaminal discectomy for recurrent lumbar disc herniation: a prospective, cohort evaluation of 262 consecutive cases. Spine 33:973-978

18. Iprenburg M (2007) Transforaminal endoscopic surgery-technique and provisional results in primary disc herniation. Eur Musculoskelet Rev 73-76

19. Jang JS, An SH, Lee SH (2006) Transforaminal percutaneous endoscopic discectomy in the treatment of foraminal and extraforaminal lumbar disc herniations. J Spinal Disord Tech 19:338343

20. Kafadar A, Kahraman S, Akboru M (2006) Percutaneous endoscopic transforaminal lumbar discectomy: a critical appraisal. Minim Invasive Neurosurg 49:74-79

21. Kambin P (1988) Percutaneous lumbar discectomy. Current practice. Surg Rounds Orthop 31-35

22. Kambin P, Gellman H (1983) Percutaneous lateral discectomy of the lumbar spine: a preliminary report. Clin Orthop 174:127-132

23. Kambin P (1992) Arthroscopic microdiscectomy. Arthroscopy 8:287-295

24. Kambin P, O’Brien E, Zhou L et al (1998) Arthroscopic microdiscectomy and selective fragmentectomy. Clin Orthop Relat Res 347:150-167

25. Kambin P, Zhou L (1997) Arthroscopic discectomy of the lumbar spine. Clin Orthop Relat Res 49-57
26. Kim MJ, Lee SH, Jung ES et al (2007) Targeted percutaneous transforaminal endoscopic diskectomy in 295 patients: comparison with results of microscopic diskectomy. Surg Neurol 68:623631

27. Kinght M, Goswami A, Patko JT (1999) Endoscopic laser foraminoplasty and a aware-state surgery: a treatment concept and 2-year outcome analyses. Arthroskopie 12:62-73

28. Knight MT, Ellison DR, Goswami A et al (2001) Review of safety in endoscopic laser foraminoplasty for the management of back pain. J Clin Laser Med Surg 19:147-157

29. Knight MT, Goswami A, Patko JT et al (2001) Endoscopic foraminoplasty: a prospective study on 250 consecutive patients with independent evaluation. J Clin Laser Med Surg 19:73-81

30. Knight MT, Vajda A, Jakab GV et al (1998) Endoscopic laser foraminoplasty on the lumbar spine-early experience. Minim Invasive Neurosurg 41:5-9

31. Krappel F, Schmitz R, Bauer E et al (2001) Open or endoscopic nucleotomy? Results of a prospective, controlled clinical trial with independent follow up, MRI and special reference to cost effectiveness. Offene oder endoskopische nukleotomie-Ergebnisse einer kontrollierten klinischen studie mit unabhangiger nachuntersuchung, MRT und unter besonderer berucksichtigung der kosten-nutzen-relation. Orthop Prax 37:164-169

32. Lee SH, Chung SE, Ahn Y et al (2006) Comparative radiologic evaluation of percutaneous endoscopic lumbar discectomy and open microdiscectomy: a matched cohort analysis. Mt Sinai J Med 73:795-801

33. Lee S, Kim SK, Lee SH et al (2007) Percutaneous endoscopic lumbar discectomy for migrated disc herniation: classification of disc migration and surgical approaches. Eur Spine J 16:431-437

34. Lee SH, Lee SJ, Park KH et al (1996) Comparison of percutaneous manual and endoscopic laser diskectomy with chemonucleolysis and automated nucleotomy. Orthopade 25:49-55

35. Lew SM, Mehalic TF, Fagone KL (2001) Transforaminal percutaneous endoscopic discectomy in the treatment of far-lateral and foraminal lumbar disc herniations. J Neurosurg 94:216-220

36. Leu H, Schreiber A (1991) Percutaneous nucleotomy with disk endoscopy - a minimally invasive therapy in non-sequestrated intervertebral disk hernia. Schweiz Rundsch Med Prax 80:364368

37. Macnab I (1971) Negative disc exploration. An analysis of the causes of nerve-root involvement in sixty-eight patients. J Bone Joint Surg Am 53:891-903

38. Mathews HH (1996) Transforaminal endoscopic microdiscectomy. Neurosurg Clin N Am 7:59-63

39. Mayer HM, Brock M (1993) Percutaneous endoscopic discectomy: surgical technique and preliminary results compared to microsurgical discectomy. J Neurosurg 78:216-225

40. Mayer HM, Brock M, Berlien HP et al (1992) Percutaneous endoscopic laser discectomy (PELD). A new surgical technique for non-sequestrated lumbar discs. Acta Neurochir Suppl (Wien) 54:53-58

41. Mixter W, Barr J (1934) Rupture of the intervertebral disc with involvement of the spinal canal. N Engl J Med 211:210-215

42. Morgenstern R, Morgenstern C, Abelleo A et al (2005) Eine studie von 144 fallen nach unterzogener endoskopischer lendenwirbelsaulenchirurgie-klassische rehabilitation im vergleich zur FPZ methode (A study on 144 cases after lumbar spine endoscopic surgery. Classical rehabilitation vs. FPZ machines system). Orthopadische Praxis 41:674-681

43. O'Hara LJ, Marshall RW (1997) Far lateral lumbar disc herniation. The key to the intertransverse approach. J Bone Joint Surg Br 79:943-947

44. Quigley MR, Bost J, Maroon JC et al (1998) Outcome after microdiscectomy: results of a prospective single institutional study. Surg Neurol 49:263-267 
45. Ramsbacher J, Kern BC, Kombos T et al (2000) Transforaminal endoscopic sequestrectomy: indications, operative technique, and first clinical experience. Neurosurg Q 10:224-227

46. Ruetten S, Komp M, Godolias G (2005) An extreme lateral access for the surgery of lumbar disc herniations inside the spinal canal using the full-endoscopic uniportal transforaminal approach-technique and prospective results of 463 patients. Spine 30:2570-2578

47. Ruetten S, Komp M, Merk $\mathrm{H}$ et al (2008) Full-endoscopic interlaminar and transforaminal lumbar discectomy versus conventional microsurgical technique: a prospective, randomized, controlled study. Spine 33:931-939

48. Sasani M, Ozer AF, Oktenoglu T et al (2007) Percutaneous endoscopic discectomy for far lateral lumbar disc herniations: prospective study and outcome of 66 patients. Minim Invasive Neurosurg 50:91-97

49. Savitz MH (1994) Same-day microsurgical arthroscopic lateralapproach laser-assisted (SMALL) fluoroscopic discectomy. J Neurosurg 80:1039-1045

50. Savitz MH, Doughty H, Burns P (1998) Percutaneous lumbar discectomy with a working endoscope and laser assistance. Neurosurg Focus 4:E9

51. Scheckenbach C, Hoogland T (1999) Endoskopische transforminale diskektomie (ETD)_Ergebnisse nach 2 jahren (Endoscopic transforaminal discectomy). Orthopadische Praxis 35:104-105

52. Schreiber A, Leu H (1991) Percutaneous nucleotomy: technique with discoscopy. Orthopedics 14:439-444

53. Schreiber A, Suezawa Y (1986) Transdiscoscopic percutaneous nucleotomy in disk herniation. Orthop Rev 15:35-38

54. Schubert M, Hoogland T (2005) Endoscopic transforaminal nucleotomy with foraminoplasty for lumbar disk herniation. Oper Orthop Traumatol 17:641-661
55. Schreiber A, Suezawa Y, Leu H (1989) Does percutaneous nucleotomy with discoscopy replace conventional discectomy? Eight years of experience and results in treatment of herniated lumbar disc. Clin Orthop Relat Res 238:35-42

56. Shim YB, Lee NY, Huh SH et al (2007) Endoscopic spinal surgery for herniated lumbar discs. J Korean Neurosurg Soc 41:241245

57. Suess O, Brock M, Kombos T (2005) Motor nerve root monitoring during percutaneous transforaminal endoscopic sequestrectomy under general anaesthesia for intra- and extraforaminal lumbar disc herniation. Zentralbl Neurochir 66:190-201

58. Suezawa Y, Schreiber A (1988) Percutaneous nucleotomy with discoscopy. 7 years experience and results. $Z$ Orthop Ihre Grenzgeb 126:1-7

59. Tsou PM, Yeung AT (2002) Transforaminal endoscopic decompression for radiculopathy secondary to intracanal noncontained lumbar disc herniations: outcome and technique. Spine J 2:41-48

60. Tzaan WC (2007) Transforaminal percutaneous endoscopic lumbar discectomy. Chang Gung Med J 30:226-234

61. van Tulder M, Furlan A, Bombardier C et al (2003) Updated method guidelines for systematic reviews in the Cochrane collaboration back review group. Spine 28:1290-1299

62. Wojcik AS (2004) Endoscopically assisted percutaneous lumbar discectomy. Ortop Traumatol Rehabil 6:259-263

63. Yasargil M (1977) Microsurgical operation for herniated disc. Adv Neurosurg 4:81

64. Yeung AT (2000) The evolution of percutaneous spinal endoscopy and discectomy: state of the art. Mt Sinai J Med 67:327-332

65. Yeung AT, Tsou PM (2002) Posterolateral endoscopic excision for lumbar disc herniation: surgical technique, outcome, and complications in 307 consecutive cases. Spine 27:722-731 